\title{
Productivity in Construction-A Critical Review of Research
}

\author{
D. A. R. Dolage and P. Chan
}

\begin{abstract}
The aim is to bring a fresh perspective to the construction productivity research agenda, which is congruent with the new demands in the construction industry and its ever changing nature. The articles which had 'construction productivity' as a keyword in the abstract, and were published in each of the three journals (JCEM, CEM and IJP) from the earliest year that the articles had been uploaded to the respective official website of each journal were identified. Out of 5862 articles searched, only 121 articles fulfilled the selection criteria, the titles of which were examined.
\end{abstract}

The past decade has witnessed the continuation of the same relentless research interest in productivity studies. The findings revealed that, in the studies: five types of productivity have been examined; five data collection methods have been deployed; research objects can be classified under seven categories. The research objects in a high number of studies are devoted to 'measurement of productivity' and 'examining the casual relationships with productivity'.

The study ascertained that the main drawbacks of past productivity studies are the strong empirical inclination of methodologies adopted and the overwhelming positivist approach to examining productivity issues. The absence of follow-up studies to investigate the validity of productivity measurement techniques and the models and to test the claims made in productivity improvement studies, is a striking feature. Another impressive finding is the lack of scholarly attention to incorporate blue-collar worker perspective, employee involvement, and social dimension into productivity research.

Key Words: Construction productivity, Critical review of Research, Worker integration, Interpretivism

\section{Introduction}

In view of the substantial share of construction sector in the whole economy, in most countries its stakeholder attention is invariably focussed on improved resource utilisation or productivity (Kazar et al., 2008). The decline or the enhancement of its economic activity has a significant direct impact on the smooth functioning of the economy and the well-being, of any country. On the one hand, the competitive business environment in the present day has increasingly compelled construction organisations to focus on their core business activities to a greater extent (Sheng, 2002). On the other, the construction industry is under tremendous pressure to be efficient due to issues such as increasing cost of energy, labour, raw material and competition.

The rational participants who perceive productivity as the ratio of output resources to input resources must strive to get higher outputs from lower inputs. In the construction industry higher productivity levels invariably lead to superior profitability, drawing the constant attention of the management. Owing to its significance to the profitability of construction projects, productivity is regarded as one of the relentlessly discussed topics in the construction industry by both the practitioners and the researchers. Nonetheless, several studies have shown that the construction industry has shown under-performance in comparison to other industries (Lee et al., Smith 2011).

The nature of construction industry has been going through a transformation over the last three decades due to a number of reasons, the two main being the emergence of off-site production (OSP) of components and the increasing engagement of subcontractors by main contractors. The growing interest in sustainable construction, rapid technological improvements and increasing labour costs should provide opportunities for OSP to serve sustainable projects (Baba et al., 2008). According to Chan and Kaka (2007), past productivity studies bore a strong positivistic tradition, often maintaining the managerial perspective. In view of ever changing construction project environment the adequacy

Eng. (Dr.) D. A. R. Dolage, CEng, FIE(Sri Lanka), BSc Eng. (Moratuwa), MSc (Reading), MA (Colombo), MBA (SJP), DBA (UniSA), Senior Lecturer, Department of Civil Engineering, The Open University of Sri Lanka.

Dr. Paul Chan, BSc (Hons), PhD, ICIOB, PCAPL, FHEA, Lecturer, School of Mechanical, Aerospace and Civil Engineering, The University of Manchester, UK. 
of existing research paradigm is questionable. The scepticism of this inadequacy has been made justifiable further by the complexities in the modern construction project since it has become increasingly difficult to benchmark performance and record, manage and transfer information and knowledge effectively (Zhao at al., 2007). Nowadays, building projects are becoming much more complex and difficult (Chan et al., 2004). This invariably adds to concerns regarding productivity in construction projects.

\section{Research gaps and objectives}

Construction productivity has been generating significant interest in both the construction industry itself and academia (Park, 2006; Ellis and Lee, 2006). Despite the many publications, a comprehensive critical review of 'productivity research in construction' with respect to levels of analysis, research objects and methodologies, has not appeared hitherto. The studies based on review of literature are gaining popularity, particularly, in order to critically review the existing body of knowledge with a view to examine plausibility of their findings and the relevance of emerging theories which are being hotly debated. However, critical reviews have been carried out in related areas such as 'competitiveness research in construction' (Flanagan et al, 2007) and 'energy and building' (Schweber and Leiringer, 2012).

The aim is to bring a fresh perspective to the construction productivity research agenda which is congruent with the new demands in the construction industry and its transient nature. This study which is based on theoretical review of recent academic publications on 'construction productivity' aims to closely examine and recapitulate the body of knowledge. It is therefore considered pertinent to summarise the progression of research on productivity in construction through a comprehensive review, and to suggest new directions for further studies. The study has two distinct research objectives. First, to examine the perception of construction productivity, progression of research interest and the spectrum of research objects currently being investigated in the existing literature concerned with 'construction productivity'. Second, to review these studies systematically with respect to each research object in order to assess the level of research and new directions for future studies.

\section{Key theoretical concepts under investigation}

Productivity is about the efficient and effective use of all resources that go into the 'production' of an activity or a process. Resources invariably include labour, materials, equipment, space, energy, finance knowledge, information and time. In the literature, the term productivity is often used interchangeably with the term efficiency (Halligan, 1994). There are different measures of productivity and the choice between these depends either on the purpose of the productivity measurement and/or data availability. The productivity measures adopted by researchers are: total factor productivity, labour productivity, construction productivity, and process productivity. The adequacy of each measure needs to be investigated in the light of the changing nature of the industry and the new demands. Further, the validity of findings and claims made based on such measures need to be verified.

The research interest in the application of concept of worker involvement, integration of perspectives of workers and managers on productivity in the construction industry is still at the nascent stage since Chan $(2006,2007)$ rekindled it to the research agenda. The possibility of widening the worker integration to encompass social relationship is also investigated.

\section{Research Method}

The relevant research publications for the study were selected from potential journals according to reputation and impact ratings as in Schweber and Leiringer (2012). A preliminary survey, carried out adopting 'Google Scholar' using keyword "construction + productivity", revealed that in the first 50 articles, more than 90 per cent are from three Journals namely, Journal of Construction Engineering and Management (JCEM), Construction Management and Economics (CME) and International Journal of Project Management (IJPM). The first two journals are prominent 'construction research' journals while the latter is a 'business and social science' journal. The other 'construction research' journals which included relevant articles are: Structural Survey, Building Research and Information, Engineering Construction and Architectural Management. It was observed that the range of objects of research covered in the articles which appeared in the three series of journals amply covered those found in the former set of 
articles. Hence, for this exercise, only the top three journals namely JCEM, CME and IJPM were considered.

In all three journals, the authors carefully went through the titles of all the articles appearing in each issue of all the volumes looking for any articles which might be concerned with 'construction productivity'. The abstracts of all the articles which had some relevance to 'construction productivity' were examined closely and the ones which had the keyword 'productivity' in the abstract were considered for the study. One of the objectives of the study was to find out the rate of publication of articles on 'construction productivity' in each journal over the years it has been in publication.

The following information was extracted from the articles:

i) The type of productivity being examined

ii) The level of analysis at which the productivity is examined.

iii) The data collection methods and methodological approaches adopted

iv) The main research object under investigation

The results obtained with respect to the above four aspects were graphically represented in terms of different types and corresponding percentage.

\section{Research Findings}

\subsection{Trends in publication of research articles on construction productivity}

The articles which had 'construction productivity' as a keyword in the abstract and published in each of the three journals from the earliest year that the articles had been uploaded to the respective official website of each journal were identified. Out of 5862 articles searched, only 121 articles fulfilled the selection criteria, the titles of which were examined. While the highest attention to construction productivity research has been paid by the JCEM (66 out of 2390; 2.76 per cent), the attention of the CME (38 out of 1672; 2.27 per cent) is of the same order. The publication of the same in IJPM (17 out of 1800; 0.94 per cent), as can be expected, has been low. Figure 1 depicts the trend of publications of these articles, as a percentage of the total number of articles published in the given year for all three journals. The articles published since 1980 having been considered, Figure 1 shows that all three journals have published articles on productivity without a continuous upward or downward trend. Since 1990 until 2012 the publication of articles follows a similar trend regarding all three journals. This indicates that research interest in productivity still holds an important position in the construction management research domain. This provides a valid justification for the study undertaken.

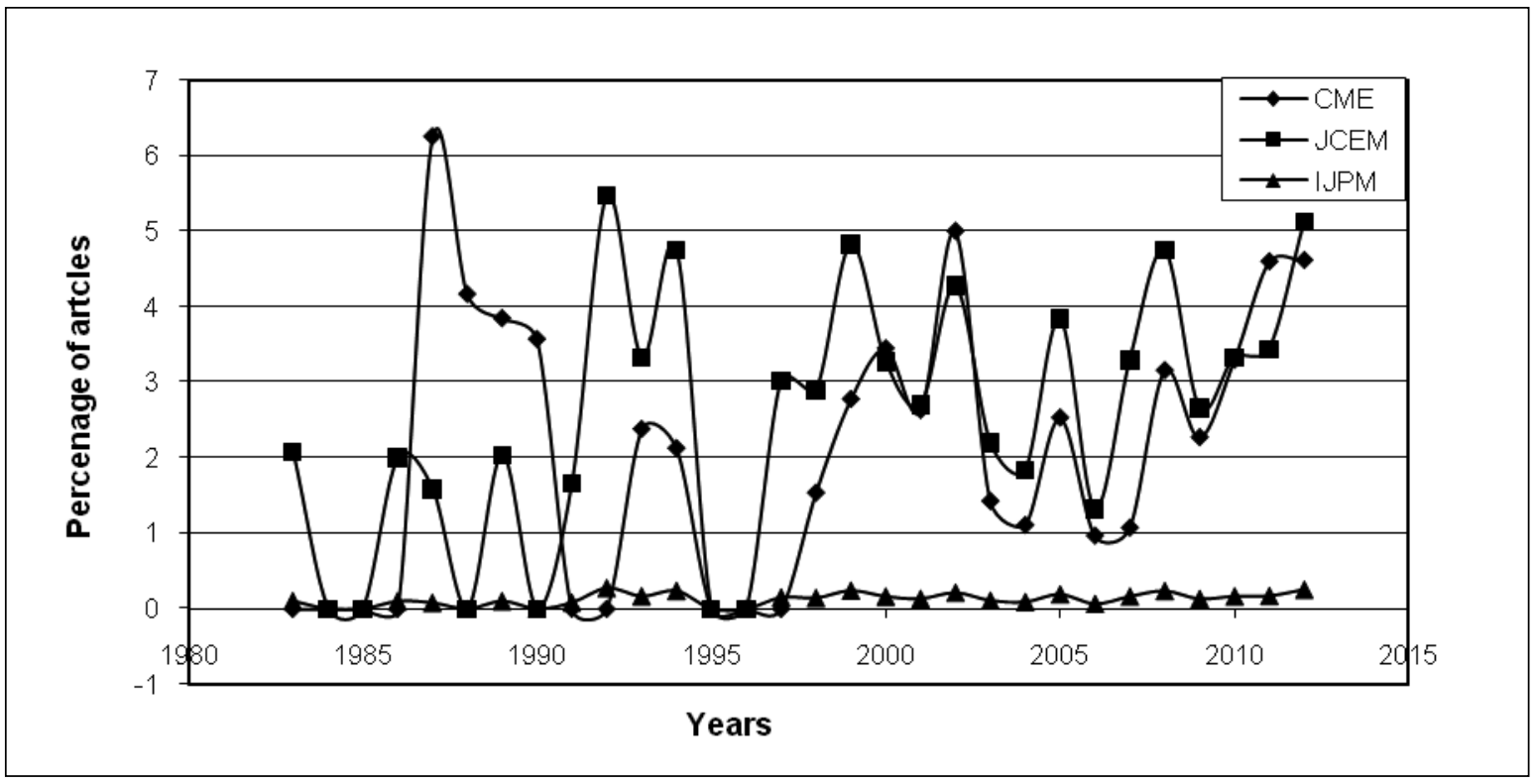

Figure 1 - Progression of Productivity Articles in Journals 


\subsection{Types of productivity and levels of analysis}

In the articles reviewed, the researchers have been interested in investigating various types of productivity, namely TFP, partial productivities such as technology and labour, process and construction. The distribution, in the descending order of application is as follows; labour (57 per cent), construction (22 per cent), process (13 per cent), TFP (6 per cent), technology (2 per cent). Since construction is a labour intensive industry, it is understandable that the highest percentage of articles are devoted to the labour productivity. Construction labour productivity has become a buzz word and one of the most frequently researched topics (Jarkas and Camille, 2012). A high number of articles (41 articles) are devoted to investigate the labour productivity of construction industry. However, evidently, in these articles, little or no scholarly attention has been paid to the changing nature of construction workforce due to growing dependence on subcontracting, OSP and increase in self employment.

The second highest percentage of research effort is expended to investigate 'construction productivity' which connotes site or industry productivity, in general. In almost all the studies which engaged questionnaire based surveys to elicit information, the respondents' perception on productivity is based on their understanding on 'construction productivity'. In some articles, although the objective of the article is to measure the construction

productivity what has really been measured is either process productivity or labour productivity (eg. Thomas et, al., 1986; Portas and AbouRizk, 1997, Artdti, 1985; Herbsman and Ellis, 1990; Goodrum et al., 2009; Goodrum and Haas, 2002). Hence, a striking feature among some of these articles is the omission to provide a clear definition of productivity.

The articles that mainly studied the productivity of operations and equipment have adopted the process productivity. It is observed that successive studies have been conducted to study productivity aspects of the same operation (eg. 4 on piling, 2 on crane, 3 on structural design, 4 on construction machinery). Although the construction industry constitutes a large number of operations and equipment that warrant studies that closely examine their productivity aspects, current research agenda has evidently failed to deal with most of them.

The reason for the low number of articles focusing on TFP is because of the difficulty to accurately determine and measure all the input resources utilised to achieve the output. Only two studies have been devoted to investigate technology productivity, one dealing with changes in material technology (Goodrum et al., 2009) and the other dealing with changes in equipment technology (Goodrum and Haas, 2002). Figure 2 graphically represents the distribution of the five types of productivity examined in these articles.

Table 2 displays the levels of analysis, types of productivity measures adopted in these articles, along with the areas that had been under investigation in these studies.

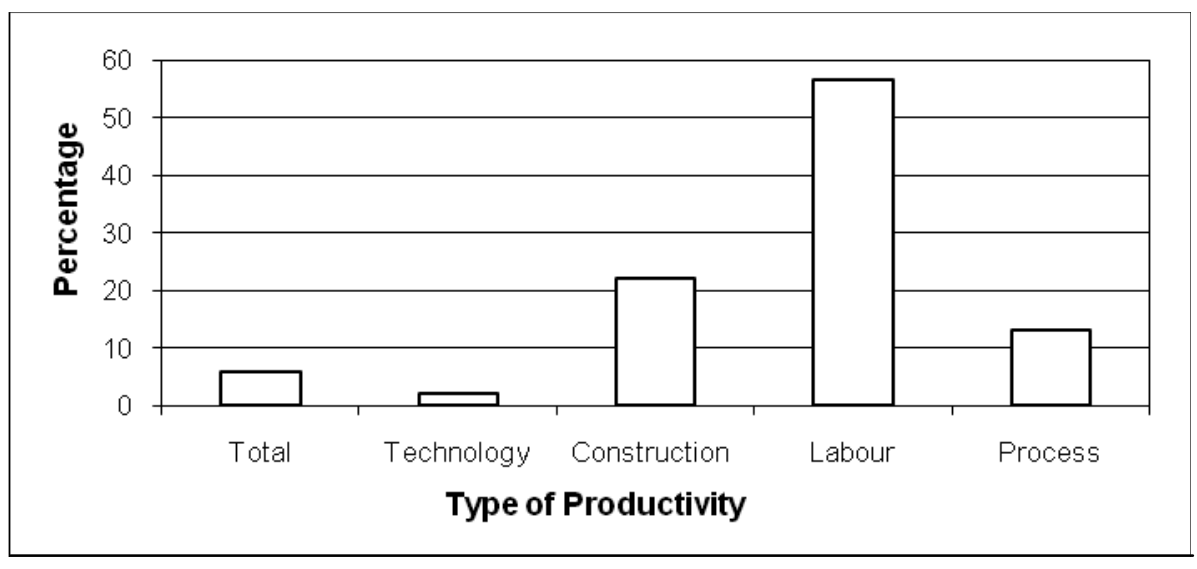

Figure 2 - Types of Productivity Explored 
Table 2 - Breakdown of Level of analysis, type and focus of productivity

\begin{tabular}{|c|c|c|}
\hline Level of Analysis & $\begin{array}{l}\text { Type of } \\
\text { productivity }\end{array}$ & Focus \\
\hline \multirow[t]{4}{*}{ Industry } & Labour & Construction industry (41) \\
\hline & Construction & Construction industry (17) \\
\hline & Partial & Construction industry (2) \\
\hline & Total & Construction industry (8) \\
\hline \multirow[t]{2}{*}{ Sector } & Labour & Housing, industrial construction, high-rise building \\
\hline & Construction & Highways (2), water and wastewater treatment, low-cost housing \\
\hline \multirow[t]{3}{*}{$\begin{array}{ll}\text { Operation } & \text { and } \\
\text { Equipment } & \end{array}$} & Labour & $\begin{array}{l}\text { Four operations, masonry wall systems, mechanical and sheet metal (2), } \\
\text { Material and technology }\end{array}$ \\
\hline & Construction & Masonry projects (2), \\
\hline & Process & $\begin{array}{l}\text { Piling (4), carne (2), structural design (3), Group of operations, } \\
\text { structural concrete, concrete batching plant, bridge, asphalt operations, } \\
\text { trenchless excavation, drywalls, Construction equipment } \\
\text { moving (2) }\end{array}$ \\
\hline \multirow[t]{2}{*}{ Trade/Contractor } & Labour & $\begin{array}{l}\text { Group of Tasks, formwork (2), concrete work (5), beam fixing, } \\
\text { bricklayer, mechanical work, fabricator, electrical and mechanical } \\
\text { contractors, labour intensive contractors, on site and offsite contractors, } \\
\text { steel drafting and fabrication (2), rebar fixing (3), masonry (2) }\end{array}$ \\
\hline & Process & Key building tasks \\
\hline
\end{tabular}

The different levels of analysis performed in these articles can be grouped under four main categories. They are in the descending order of application; industry (57 per cent), Operations/Equipment (20 per cent), Trade/Contractor (16 per cent) and sector (7 per cent). A large majority of studies which have explored different types of productivity industry-wide are based on questionnaire surveys. Since the responses to the questionnaires are based on accumulated experience gained over the years being in the industry, they reflect the industry-wide perception. Further, the availability of panel data on information required to compute different types of productivity has encouraged the proliferation of a large number of studies examining the construction industry, holistically. Productivity being a phenomenon associated with social dimension, the validity of findings made in such studies may have room for error. Alternatively, if these studies had been focussed on different industry sectors instead of the industry as a whole, the validity of findings could have been improved.

Only a minute percentage of articles having been dedicated to examine productivity at industry sector indicate the lack of rigor in the present research agenda. Of the studies 57 per cent considering the industry holistically, compared to 7 per cent of studies doing the same on the industry sector is grossly inadequate.

A substantive number of productivity studies on associated with various operations and equipment are shown in Table 2. In a similar manner, a good number of articles have looked into the productivity of some trades and tasks of specific contractors. However, as shown in Table 2, a large majority of these trades are from a limited range (eg concreting of slabs, beams and columns, formwork and structural steel fixing). Mostly, these are related to concrete work or to tasks for which data available in abundance or to tasks which are easily measurable. A likely explanation for the situation is 'methodolatory' where researchers tend to conduct research, particularly positivists, to suit to the methods and data availability. Figure 3 displays the percentage distribution of levels of analysis adopted in these articles. 


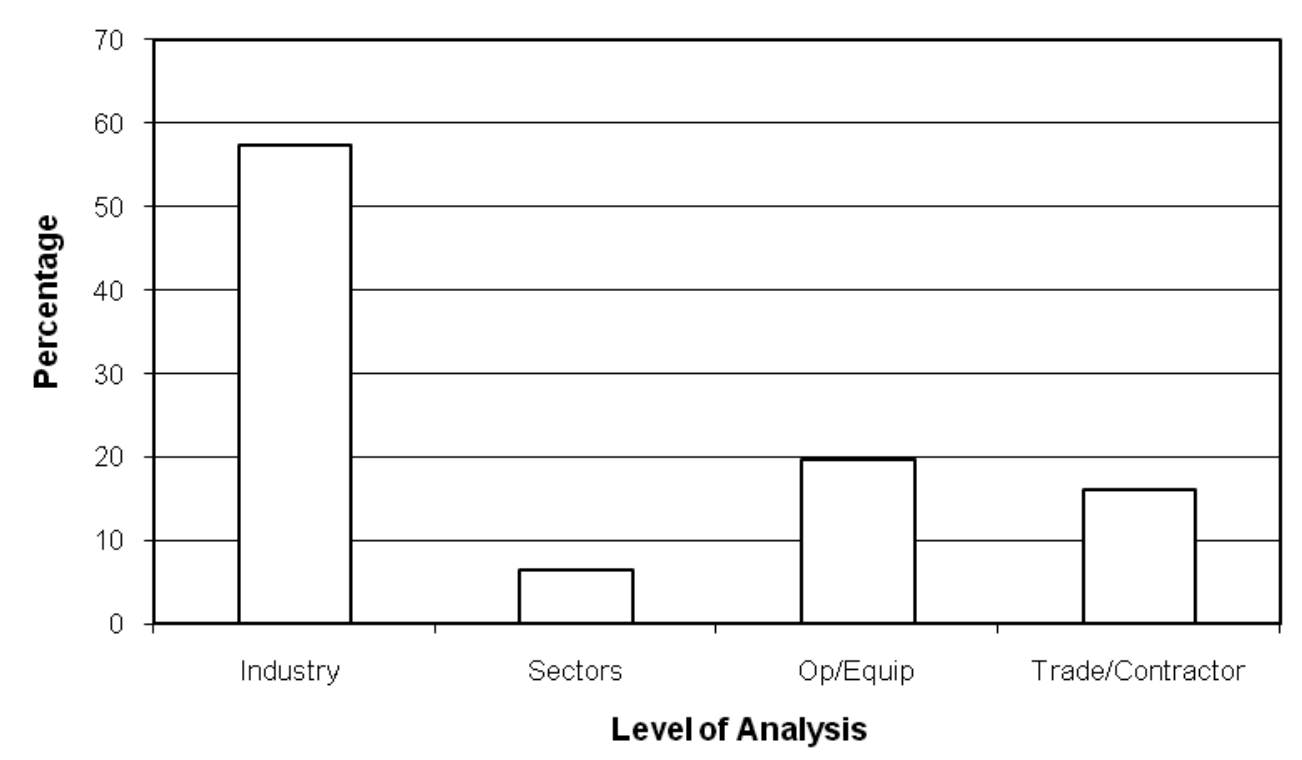

Figure 3 - Level of Analysis

\subsection{Data collection methods and methodologies}

As one of the steps of the study, data collection methods and research approaches or methodologies deployed in the articles were examined. Unsurprisingly, most articles adopted more than one data collection method to varying degrees in their investigations; for example, every article had data coming in from literature review. Therefore, in order to keep the analysis simple, the data collection method that had the predominant bearing on their findings was picked for this study. Figure 4 shows graphically how productivity researchers have adopted the five different types of data collection methods.

The highest percentage ( 35 per cent) of studies have adopted data maintained over a period at site or project offices concerning relatively stable, established, repetitive and simple construction activities. On some occasion, the analysis is based on a single data set (case study) and on the others the same was based on different data sets. However, the researchers seldom refer to possible differences among contractors regarding data collection and recording, which concern, if not addressed, could invalidate the findings. In 23 per cent of studies, the type of method adopted to collect data is the questionnaire survey. A great majority of studies are devoted to identify and rank factors influencing productivity. Scholars have not been adequately concerned about differences in defining factors on which perceptions are sought and the significance of providing productivity definitions to respondents. Construction industry data bases and industry panel data are used in 19 per cent of studies. While in 11 per cent of studies field measurements are used, in 12 per cent of studies literature surveys are adopted.

This also shows a high percentage (91 per cent) of articles use site data, questionnaire surveys, field measurements, site observations and data bases evidencing the acute empiricist inclination in the contemporary productivity studies. The empirical studies favour positivist research approach and therefore all these articles are based on positivism. Positivism was defined as a scientific methodology that aims to reach the laws of human behaviour and social life (Tekin and Kitaman, 2013). The positivist approach pays scant attention to the complexity of social construction and interactions in its attempt to explain them through a onedimensional linear cause-and-effect relationship.

It is heartening to note that only a small percentage (12 out of 136, 09 per cent) of studies are based on pure review of literature, an approach which has some characteristics of interpretivist research. Interpretivism is a school of thought that builds on the meaning of social interactions. Further, most of the studies which adopted questionnaire surveys elicit perceptions of respondents on productivity related questions. However, the accuracy of 
findings in these studies is questionable particularly because productivity being a complex phenomenon, respondents could have different perceptions. The most conspicuous methodological feature of productivity studies concerns the involvement of positivist versus interpretivist approaches.

Despite the adoption of advanced statistical techniques (eg. correlation, multivariate, principal component analysis and structural equation modelling), it can be argued that the rigid theory testing methodology of the positivist research paradigm cannot address the specific research context needed to understand a complex phenomenon like productivity.

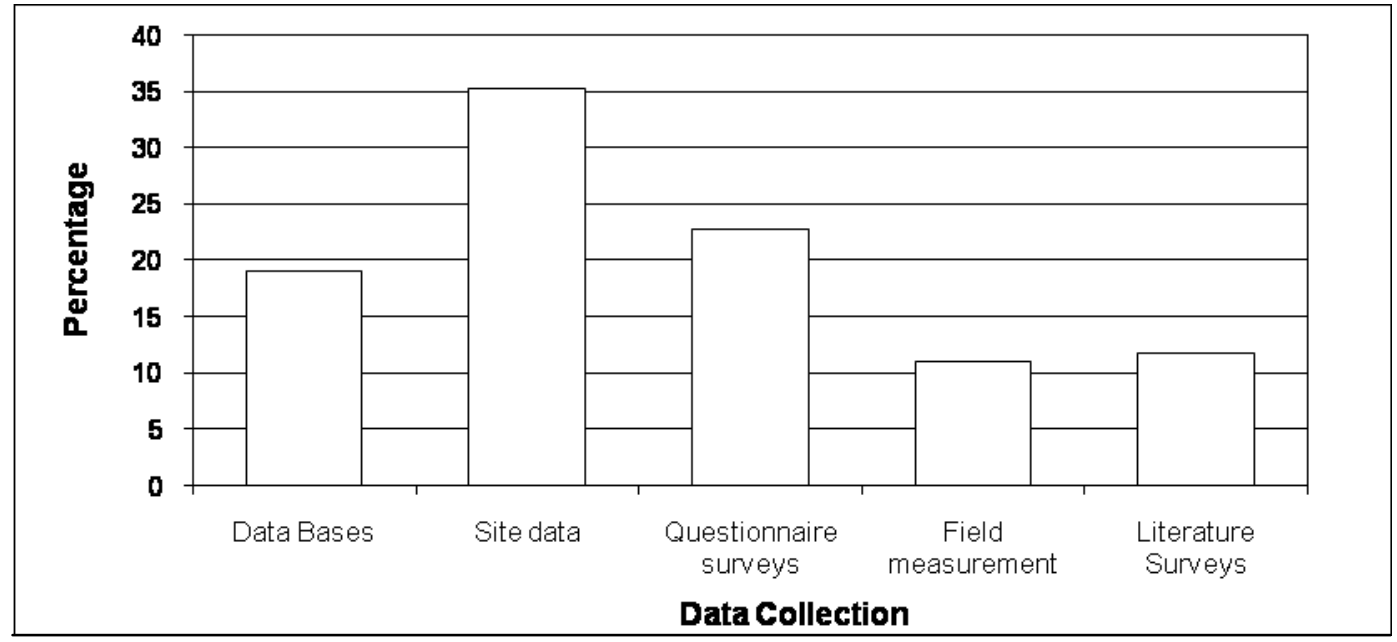

Figure 4- Data Collection Methods

\section{$5.4 \quad$ Types of research objects}

Each article fundamentally has been devoted to examine one type of productivity discussed earlier, at a particular level of analysis, with respect to a particular predominant research object. The different research objects investigated in the articles can be clustered into six different generic groups namely trends, measurement, means and assessment of improvement, identification and ranking of influencing factors, nature and causal relationships. The number of articles, percentages and focuses are presented in Table 3 , under each generic group of research object.

The research object of the largest proportion of articles (49 out of 136; 36 per cent) are basically concerned with productivity measurement although the stated research objects had been; assessment (25 out of 49 ), measurement (14 out of 49 ) and modelling (10 out of 49 ). In order to simplify the analysis and comparison, .it was decided to group them all under productivity measurement since all these are associated with measurement. A striking observation is the growing adoption of Artificial Neural Network (ANN), a technique adopted when variables involved are too complex for the human brain to handle, to model construction productivity (eg. Portas and AbouRizk, 1997; Sonmez1 and Rowings, 1998; Ok and Sinha, 2006; Zayed at al., 2005). Some other studies had adopted other advanced statistical models (eg. Zayed and. Halpin, 2005) and software programmes (eg. Everett and Slocum, 1993). The interest in the use of advanced techniques to estimate productivity can be ascribed to complexities in measurement. However, the concern still remains whether the intense research effort to measure productivity using dominant positivist approach is still valid when social and human facet of productivity have been ignored.

Almost an equal number of articles (48 out of 136; 35 per cent) investigate the causal relationship of productivity with different attributes, namely, Technology (5), Operation (4), Design (4), Motivation (6), Benchmarking (6), Buildability (4), Physical environment (3), Labour deployment (6), Change orders (4), Management practices/actions (8); the number of articles are depicted in parentheses.

Technology- The articles examine how changes in material and equipment technology cause improvements in productivity. Also some examine how new technologies such as 
advance machine guidance systems improve process productivity.

Operation-The articles are mainly dealing with the assessment of productivity of standard operations like concreting, fabrication and joining.

Design- The research objects of articles broadly falls in to two areas; impact on construction productivity due to changes in the design while construction in progress; impact on construction productivity due to improvement in the design process.

Motivation-The impact of operative motivation and training on productivity and the impact of demotivating factors on productivity are dealt with in these articles.

Benchmarking-The articles are devoted to explain how benchmarking could be effectively used to improve productivity. The articles are focusing on benchmarking across countries and across contractors.

Buildability- The influence of buildability on productivity of operations and quantification of the influence in its relationship with productivity have been dealt with in these studies.

Physical environment-The causal relationships of inhibitors such as climatic effects, rainfall and thermal effects with the productivity are quantified in these articles.

Labour deployment-The impacts of scheduled overtime, overmanning, shift work on productivity are assessed in these articles.

Change orders-The contribution of change orders or construction changes to labour productivity are investigated in these articles.

Management practices/actions-The importance of management practices and actions such as BPR, quality assurance and participatory management on productivity are assessed in these articles.

The purpose of a substantial number of articles (16 out of $136 ; 12$ per cent) is to identify and rank the factors influencing productivity. This type of studies has been carried out in different countries: USA (Herbsman and Ellis, 1990; Dai et al. 2009), Singapore (Lim and Alum, 1995), Thailand (Makulsawatudom et al., 2004) and Indonesia (Kaming et al.1998) to name a few. It was observed that there is incongruence among the factors identified and variance in the classification of factors. Further, the utility of these studies is limited because these factors are country specific and has less relevance to the construction industry of another country.

The research object of a reasonable number of articles (14 out of 136; 10 per cent) is to explore means and assessment of productivity improvement. These studies are separately looking into two aspects of productivity; namely areas where productivity improvement is possible (eg. Arditi,1985; Arditi and Mochtar,1996) and productivity improvement techniques (Cottrell, 2006; Chan and Kaka, 2007; Han et al.2008, Minchin et al.2008). It is striking to note that follow up studies have not been conducted to empirically verify the validity of claims and promises made in productivity improvement studies.

Understandably, only a small number of studies (5 out of 136; 4 per cent) explore the productivity trends and these studies are focusing on TFP or labour productivity of the construction industry. Four of these studies have been carried out in the USA (Allmon, 2000; Arditi and Mochtar, 2000; Teicholz, 2001 Rojas and Aramvareekul, 2001) and of which three are looking into the labour productivity trends. Chau (1993) has conducted a study on estimating industry-level productivity trends in the building industry of Hong Kong.

Again, only a small percentage of studies (4 out of 136 ; 3 per cent) look into the nature of construction on productivity and theories of productivity. Figure 5 graphically illustrates the distribution of research objects. 
Table 3 - Distribution of Research objects

\begin{tabular}{|c|c|c|c|c|}
\hline \multirow{2}{*}{$\begin{array}{l}\text { Groups of Research } \\
\text { Objects }\end{array}$} & \multirow{2}{*}{\multicolumn{2}{|c|}{ Focus }} & \multicolumn{2}{|c|}{ Article } \\
\hline & & & Number & Percentage \\
\hline Productivity trends & $\begin{array}{l}\text { Labour productiv } \\
\text { countries }\end{array}$ & and total factor productivity of different & 5 & 4 \\
\hline \multirow{3}{*}{ Measurement } & Assessment (25) & \multirow{3}{*}{$\begin{array}{l}\text { Sub contracting, scheduled overtime, } \\
\text { change orders, scheduled overtime }\end{array}$} & \multirow{3}{*}{49} & \multirow{3}{*}{36} \\
\hline & Measurement (14) & & & \\
\hline & Modelling (10) & & & \\
\hline $\begin{array}{l}\text { Means and } \\
\text { assessment of } \\
\text { Productivity } \\
\text { Improvement }\end{array}$ & \multicolumn{2}{|c|}{$\begin{array}{l}\text { Design process, Measures to be taken, motivation, Productivity } \\
\text { improvement officer, design integrated process/planning, } \\
\text { quality circles, }\end{array}$} & 14 & 10 \\
\hline $\begin{array}{l}\text { Identification and } \\
\text { ranking of factors }\end{array}$ & \multicolumn{2}{|c|}{ Influencing the industry } & 16 & 12 \\
\hline $\begin{array}{l}\text { Nature and } \\
\text { Theories }\end{array}$ & \multicolumn{2}{|c|}{$\begin{array}{l}\text { Variability of productivity, implications of nature, field studies, } \\
\text { baseline theory and practice }\end{array}$} & 4 & 3 \\
\hline \multirow{10}{*}{$\begin{array}{l}\text { Causal } \\
\text { relationships }\end{array}$} & \multicolumn{2}{|l|}{ Technology (5) } & \multirow[t]{10}{*}{48} & \multirow[t]{10}{*}{35} \\
\hline & \multicolumn{2}{|l|}{ Operation (4) } & & \\
\hline & \multicolumn{2}{|l|}{ Design (4) } & & \\
\hline & \multicolumn{2}{|l|}{ Motivation (6) } & & \\
\hline & \multicolumn{2}{|l|}{ Benchmarking (4) } & & \\
\hline & \multicolumn{2}{|l|}{ Buildability (4) } & & \\
\hline & \multicolumn{2}{|c|}{ Physical environment (3) } & & \\
\hline & \multicolumn{2}{|c|}{ Labour Deployment (6) } & & \\
\hline & \multicolumn{2}{|l|}{ Change orders (4) } & & \\
\hline & \multicolumn{2}{|c|}{ Management practices/actions (8) } & & \\
\hline
\end{tabular}

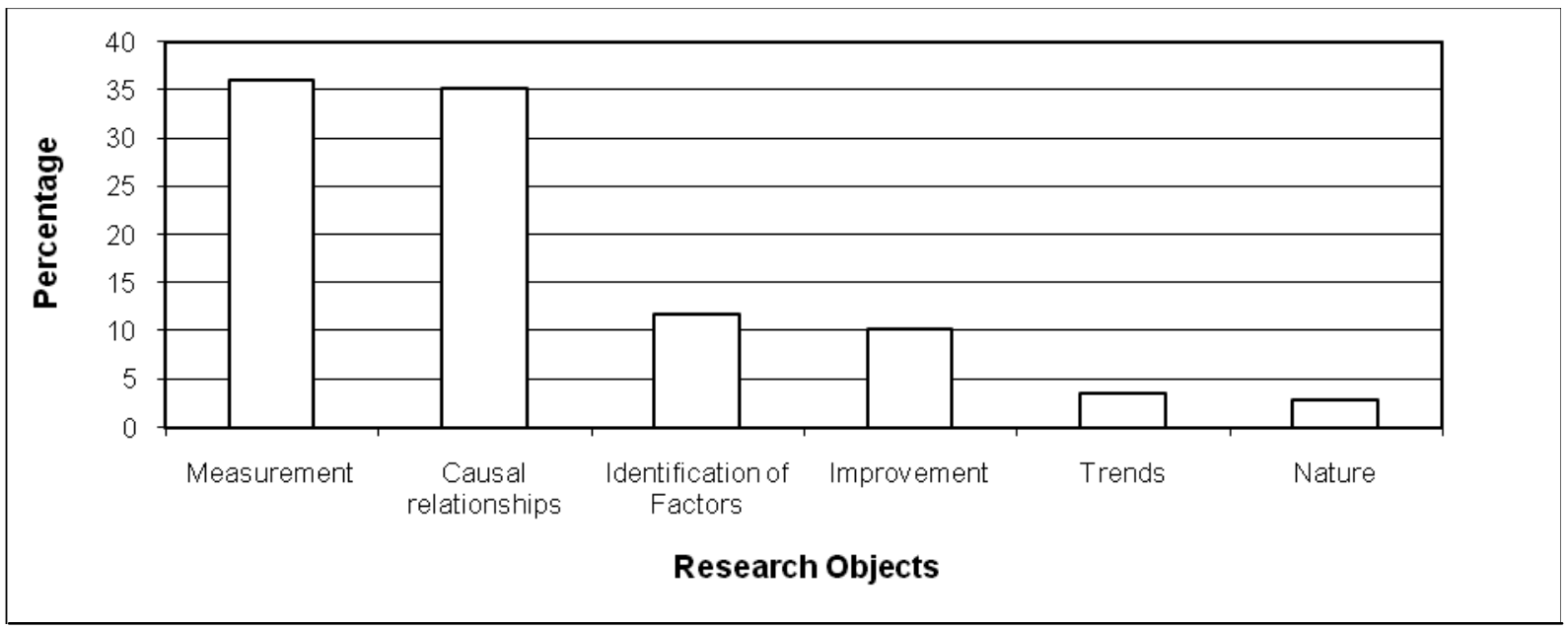

Figure 5-Distribution of Research Objects

\section{Implication of findings on theory, practice and policy}

An impressive finding of the study is the overwhelming engagement of the positivist research in construction productivity research. The positivist approach ignores the complexity of social matters and interactions, and productivity being a concept associated with humans, this research approach alone is not adequate to understand the exact context of construction productivity. The construction scholars should adopt a research paradigm like interpretivist approach which is understandably new to construction productivity research domain.

According to the review of articles, the scholars have investigated the construction productivity in a managerial perspective while paying scant attention to worker perspective. Construction professionals are subjected to a plethora of occupational demands that can have a negative effect on their psychological wellbeing (Love et al., 2010). These demands can have an adverse 
influence on individual and organizational productivity. The studies need to be undertaken to investigate new areas like the worker happiness, nature of self and social supports, work stress and mental health among construction professionals directly focussed on worker wellbeing. These aspects which are directly associated with workers' social construction can only be addressed through multidisciplinary and inductive research. Therefore, in this context, interpretivism is a much better choice than positivism.

The findings suggest that emphasis on research objects such as productivity measurement and ranking of factors influencing productivity is overwhelming and the neglect of much pertinent research objects like worker involvement and social dimension is noticeable. The research effort should be diverted to investigate less debated areas like employee involvement, social dimension to productivity and integration of blue collar and white collar worker perspectives on productivity. The managers should be made aware of the necessity to look at the productivity improvement holistically considering the perspectives of blue collar workers too. The industry professionals should be concerned about the social dimension and get the workers involved in productivity issues and see that they are content and happy. The findings also suggest that productivity improvement studies should be followed up to empirically determine the veracity of these studies. The findings of the study will be useful to administrators of research grants to make more funds available to prospective studies on less researched areas identified above and to prospective studies that adopt new approaches. The industry professionals should be concerned about the social dimension and get the workers involved in productivity issues and see that they are content and happy.

With the little evidence shown in the study, the percentage of 'construction productivity' research is higher in construction journals than in the business and social science journals. The scholarly interest in publication of productivity research in business and social science journals need to be examined more closely. The interest among the scholars who wish to publish in this domain should be promoted in order to bring in the multidisciplinary approach to construction productivity research.
The articles reviewed refer to two productivity measures namely construction productivity (abstract measure) and process productivity (physical measure), in addition to the conventional ones such as TFP and partial productivities such as labour and technologies. The drawbacks of using 'construction productivity' which is not a well defined productivity measure and the necessity of defining productivity measure to lessen the subjectivity of findings were highlighted. The process productivity was formally recognised and defined. The construction scholars need to take the above concerns into consideration in future studies. They should also divert their attention to less researched types of partial productivities.

\section{Conclusion}

This paper has sought to review the published research on 'construction productivity'. It ascertained that the main drawbacks of past productivity studies are the strong empiricist inclination of methodologies adopted and the overwhelming positivist approach to examining productivity issues.

A large number studies have explored research objects such as measurement, ranking of influencing factors and improvement techniques related to productivity. The absence of follow up studies to investigate the validity of productivity measurement techniques and the models and to test the claims made in productivity improvement studies, is a striking feature. Another impressive finding is the lack of scholarly attention to incorporate blue collar worker perspective, employee involvement, and social dimension into productivity research. Hence, in future, scholarly attention should be drawn to these areas so that new studies can be taken up.

The encouragement to adopt interpretivist methodology instead of positivist approach for research studies is a necessity to bring insights into existing knowledge on construction productivity. It proves the existence of a vacuum of interpretivist research on productivity and cohabitation of approaches, interpretivism and positivism, should be encouraged. Further, this will encourage new audience of researchers adept at researching social dimension to investigate construction productivity. This provides opportunities to construction researchers to publish in business and social science journals. 
The articles reviewed refer to two productivity measures namely construction productivity (abstract measure) and process productivity (physical measure) and in this article they have been formally recognised and defined.

\section{References}

1. Abdelhamid, T. S., and Everett, J. G., (1999) "Time Series Analysis for Construction Productivity", Experiments", Journal of Construction Engineering and Management, Vol. 125, No.2, pp. 87-95.

2. Allmon, E., Haas, C. T., Borcherding, J. D .and Goodrum P. M. (2000) , “U.S. Construction Labor Productivity Trends, 1970-1998", Journal of Construction Engineering and Management, Vol. 126, No. 2, pp.97-104.

3. Arditi, D.(1985), "Construction Productivity Improvement", Journal of Construction Engineering and Management, Vol.3, pp.1-14.

4. Arditi, D. and Mochtar, K. (1996), “Productivity Improvement In The Indonesian Construction Industry", Construction Management and Economics, Vol 14, pp. 13-24.

5. Arditi, D. and Mochtar, K. (2000), "Trends in productivity improvement in the US construction industry", Construction Management Economics", Vol. 18, pp.15-27.

6. Chan, P. W. and Kaka, A. (2007), “Productivity Improvements: Understand the Workforce Perceptions of Productivity First", Personnel Review, Vol. 36 No. 4, pp. 564-584.

7. Chau, K. W. (1993), “Estimating industry-level productivity trends in the building industry from building cost and price data", Construction Management and Economics Vol. 11, pp. 370-383.

8. Cottrell, D. S. (2006), “Contractor Process Improvement for Enhancing Construction Productivity", Journal of Construction Engineering and Management, Vol. 132, No.2, pp. 189-196.

9. Crawford, P. and Bernard Vogl, B. (2006), "Measuring Productivity in The Construction Industry", Building Research $\mathcal{E}$ Information, 34(3), 208-219.

10. David W. Halligan,D. W., Demsetz, L. A., Brown, J. D., and Pace, C. B. (1994), “ActionResponse Model And Loss of Productivity in Construction", Journal of Construction Engineering and Management, Vol. 120, No.1, pp. 47-64.
11. Ellis Jr, R. D., and Lee, S. H. (2006), “Measuring Project Level Productivity on Transportation Projects", Journal of Construction Engineering and Management, Vol. 132, No.3, pp. 314-320.

12. Everett, J. G. and Alexander H. Slocum, A. H. (1993), “Cranium: Device for Improving Crane Productivity and Safety", Journal of Construction Engineering and Management, Vol. 119, No.1, pp. 23-39.

13. Goodrum, P. M and Haas. C. T. (2002), "Partial Factor Productivity and Equipment Technology Change at Activity Level in U.S. Construction Industry" Journal of Construction Engineering and Management, Vol.128, No.6, pp. 463-472.

14. Goodrum; P. M, Zhai, D. and Yasin, M. F.(2009), Relationship between Changes in Material Technology and Construction Productivity, Journal of Construction Engineering and Management, Vol. 135, No.4, pp. 278-287.

15. Goodrum, P. M., Haas, C. T., Caldas, C., Zhai;D., Yeiser, J. and Homm, D. (2011), “Model to Predict the Impact of a Technology on Construction Productivity", Journal of Construction Engineering and Management, Vol. 137, No.9, pp. 678-688.

16. Herbsman, Z. and Ellis, R. (1990), "Research of factors influencing construction productivity", Construction Management Economics", Vol. 8, pp.49-61.

17. Jarkas, A. M. and Bitar, C. G (2012), "Factors Affecting Construction Labor Productivity in Kuwait", Journal of Construction Engineering and Management, Vol. 138, No.7, pp. 811-820.

18. Jason Portas, J., J.and AbouRizk, S. (1997), "Neural Network Model for Estimating Construction Productivity", Journal of Construction Engineering and Management, Vol. 123, pp.399-410.

19. Jiukun Dai1, J., Paul M. Goodrum, P. M., and William F. Maloney, W. F., (2009)," Construction Craft Workers' Perceptions of the Factors Affecting Their Productivity", Journal of Construction Engineering and Management, Vol. 135, No. 3, pp. 217-226.

20. Kaming, P. F., Holt, G. D., Kometa, S. T., Olomolaiye, P.O. (1998), "Severity Diagnosis of Productivity Problems--A Reliability Analysis", International Journal of Project Management, Vol. 16, No. 2, pp. 107-113.

21. Langford, D. A., H. El-Tigani1, H. And Marosszeky, M. (2000), “Does Quality Assurance Deliver Higher Productivity?", Construction Management and Economics, Vol.18. pp. 775-782.

22. Lim, E. C. and Alum, J.(1995), “Construction Productivity: Issues Encountered by Contractors 
in Singapore", International Journal of Project Management, Vol.13, No.1, pp. 51-58.

23. Makulsawatudo, A, Sinthawanarong, K, and Emley, M.(2004), “Critical Factors Influencing Construction Productivity in Thailand", The Journal of KMITNB, Vol.14, No.3

24. Naoum, S. and Hackman, J. (1996) “Do site Managers and the Head Office Perceive Productivity Factors Differently? "Engineering, Construction and Architectural Management" Vol.1, 2, pp. 147-160.

25. Ok, S. C. and Sunil K. Sinha, S. K. (2006), "Construction Equipment Productivity Estimation using Artificial Neural Network Model", Construction Management Economics", Vol. 24, pp. 1029-1044.

26. Park H. S. (2006), "Conceptual Framework of Construction Productivity Estimation", KSCE Journal of Civil Engineering, Vol. 10, No. 5. pp. 311317.

27. Peter E. D. Love, P. E. D, Edwards, D. J and Irani, Z. (2010), "Work Stress, Support, and Mental Health in Construction", Journal of Construction Engineering and Management, Vol. 136, No.6, pp. 650-658.

28. Rojas, E. M and Aramvareekul, P., (2003), "Is Construction Labor Productivity Really Declining?, Journal of Construction Engineering and Management, Vol.129: No 1. pp. 41-46.

29. Sonmez, R. and Rowings, J. E. (1998), "Construction Labor Productivity Modeling With Neural Networks", Journal of Construction Engineering and Management, Vol. 124, No. 6, pp.498-504.

30. Tarek M. Zayed, T. M. and Halpin, D. W., (2005), "Pile Construction Productivity Assessment", Construction Management Economics", Vol. 131, pp. 705-714.

31. Teicholz, P. (2001), “U.S. Construction Labor Productivity Trends, 1970-1998", Journal of Construction Engineering and Management, Vol. 112, pp.245-258.

32. Thomas, H. R., Mathews, C. T. and. Ward, J. G (2006), "Learning Curve Models of Construction Productivity", Journal of Construction Engineering and Management, Vol. 112, pp.245-258.

33. Zayed,T. M., Halpin, D. W. and Basha I. M. (2005), "Productivity and Delays Assessment For Concrete Batch Plant-Truck Mixer Operations", Construction Management and Economics, Vol.23. pp. 839-850.
34. Zayed, T. M. and Halpin, D. W. (2005), "Productivity and Cost Regression Models for Pile Construction", Journal of Construction Engineering and Management, Vol. 131, No.7, pp. 779-789. 